\title{
Biojet Fuels and Emissions Mitigation in Aviation: an Integrated Assessment Modeling Analysis
}

\author{
Marshall Wise*, Matteo Muratori ${ }^{1}$, Page Kyle
}

\begin{abstract}
Although the aviation sector is a relatively small contributor to total greenhouse gas emissions, it is a fast-growing, fossil fuel-intensive transportation mode. Because aviation is a mode for which liquid fuels currently have no practical substitute, biofuels are gaining attention as a promising cleaner alternative. In this paper, we use the GCAM integrated assessment model to develop scenarios that explore the potential impact of biojet fuels for use in aviation in the context of broader climate change mitigation. We show that a carbon price would have a significant impact on the aviation sector. In the absence of alternatives to jet fuel from petroleum, mitigation potential is limited and would be at the expense of aviation service demand growth. However, mitigation efforts through the increased use of biojet fuels show potential to reduce the carbon intensity of aviation, without a significant impact on bioenergy use in the rest of the energy system for carbon mitigation. The potential of biofuel to decarbonize air transport is significantly enhanced when carbon dioxide capture and storage (CCS) is used in the conversion process to produce jet fuels from biomass feedstock.
\end{abstract}

\section{Keywords}

Biofuels; Biojet; Alternative Fuels; Aviation; Air Transport Emissions; Climate Change Mitigation.

\section{Introduction}

The aviation sector is a relatively small contributor to total greenhouse emissions: global domestic and international air travel accounted for only about $4 \%$ and $6 \%$ of total transport sector greenhouse gas emissions in 2010, respectively (Sims et al., 2014), and overall air transport is responsible for roughly $2-4 \%$ of all anthropogenic carbon emissions (IATA, 2015, Schäfer and Waitz, 2014). However, aviation is a fossil fuelintensive transportation mode that has grown significantly over the last decades, and in particular in the recent years: a demand growth increase of more than 5\% per year over 
2010-2014 (IATA, 2015). Aviation demand is expected to continue to grow over the next two decades as population and incomes rise. Boeing forecasts an increase of about $5 \%$ per year until 2034 for both passenger and cargo traffic (Boeing, 2015).

In light of expected demand growth, complete reliance on petroleum-derived fuels, and the environmental impact of related emissions, the aviation sector has been under some scrutiny to reduce future emissions. The International Civil Aviation Organization (ICAO) was directed by the Kyoto Protocol to explore pathways for mitigating aviation emissions. In 2008, the aviation industry adopted a goal of maintaining carbon-neutral growth in global aviation from the year 2020 and a second goal of reducing emissions by $50 \%$ relative to 2005 by 2050 (IATA, 2015b). Emissions from international aviation are especially challenging to mitigate because they are released along routes where no single nation has regulatory authority (McCollum et al., 2010). In terms of specific policies, the EU Emissions Trading Scheme (ETS) covers aviation, but implementation has not been straightforward with questions of coverage of intra- and extra- EU flights. The EU suspended ETS coverage of aviation in 2012 (EU 2013), and future plans are not clear. In the United States, though there is no restriction on carbon emissions from aviation, several government agencies are coordinating efforts to reduce emissions as well as research and increase the use of biojet fuels for aviation in both civilian and military uses (Civil Aviation Organization (2012)). In addition, biojet fuels are included in the U.S. Renewable Fuels Standard (RFS2) (EPA 2015).

Regardless of binding legislation and emissions constraints, industry groups have proceeded with voluntary targets and plans to reduce the carbon intensity of aviation, for example through the ICAO plan. Some of this planning may be in order to prepare or get ahead of environmental mandates. Some of the reason may be for good public relations of the industry. Although on a per-unit basis (i.e. passenger-km), commercial air travel is currently relatively on par with light duty vehicle travel (Sims et al., 2014, Chapman, 2007), aviation is under pressure to keep up with carbon-intensity reduction in road transport. Moreover, there may be a perception problem that air travel itself is a luxury or not as crucial as other forms of transportation so that emissions from aviation for tourism, for example, are something that should be minimized (Mayor and Tol, 2010).

\section{Biojet Fuels}

Because aviation service is a growing demand, both domestically and globally, for which liquid fuels have no practical substitute, biofuels are gaining attention as a promising solution to reduce the environmental footprint and energy security concerns of air transportation. Most long-term integrated assessment studies ${ }^{2}$ have assumed that air transportation would be among the last or most difficult major energy demand sectors to

2 We use "integrated assessment modeling" here to mean the class of models that integrates long-run global energy, agriculture, land use, and emissions comprehensively but with different degrees of detail in component sectors. 
decarbonize (see Clarke et al. 2014 for an overview). Alternative aviation energy sources have not been a focus for these types of modeling exercises. Within the transportation sector, it is also generally thought that some portion of the passenger vehicle sector could be serviced by low-carbon electricity or hydrogen in order to decarbonize or to reduce reliance on liquid fuels, including biofuels. Since electrification of the aviation sector is more difficult to conceive than for road passenger vehicles, even at a century time scale, aviation may be a significant market for biofuels in the long run.

Feasibility studies, and life cycle analyses about alternative jet fuels, have been the focus of numerous studies. International aviation industrial organizations such as ICAO and the International Air Transport Association (IATA) have published technology roadmaps in order to meet industry carbon emissions goals over the coming decades, including the adoption of biojet fuels (e.g., IATA 2015b). The IPCC published a comprehensive overview of the state of technology and policy related to aviation fuels and emissions as part of its Fifth Assessment Report (Sims et al.2014). The U.S. National Renewable Energy Laboratory (NREL) published an assessment of technology pathways and the feasibility of producing substantial quantities of biojet fuels in the U.S. (Milbrandt et al. 2013). Several detailed Life Cycle Analysis (LCA) studies have been published recently looking at biojet technology pathway resource requirements and sustainability considerations such as net carbon footprints (see, for example, Agusdinata et al. 2011 and Han et al. 2013). The Aviation Integrated Model (AIM), which links several components of the aviation sector with technological and structural detail, has considered biojet fuels as an important component of potential emissions reductions in aviation (Dray et al. 2014).

Several economic modeling analyses have been published on the impact of carbon limits on aviation. Hofer et al. (2010) performed an econometric study of carbon taxes on U.S. aviation and found that decreases in aviation demand induced by increases in airline fares could be offset by increases in the use of and emissions from passenger vehicles. Winchester et al. (2011) found while exploring the impact of then-proposed emissions cap and trade policies in the U.S. that the aviation sector was more costly and difficult to mitigate than the rest of the energy system. Their study, which did not include biojet fuels, found that the introduction of a carbon price would raise fuel prices and decrease the growth in demand for aviation, but that emissions would still increase substantially from current levels under relatively high carbon prices. Krammer et al. (2013) used the AIM model in conjunction with scenarios from integrated assessment models (including MiniCAM, a forerunner of the modeling framework used in this paper) to study biojet fuels. They showed that although biojet fuels could offset growth in aviation sector carbon emissions, other greenhouse gases emitted from the aircraft such as nitrous oxides would still grow with demand and need to be considered in meeting climate goals.

Our goal in this paper is to build on the growing literature by using a global integrated assessment modeling framework to consider the potential and impact of biojet fuels for 
mitigating carbon emissions in the context of the broader, multi-sector energy and land use systems. In this study, we analyze the potential and the effects of production and use of bio-based jet fuels for aviation under a hypothetical future scenario where global energy system carbon dioxide emissions are reduced to specified targets ${ }^{3}$. Using the transportation demand sector of the Global Change Assessment Model (GCAM), we evaluate the potential demand for aviation biofuels in the context of the growing global demand for air transportation, integrated with the competing uses of bioenergy in other sectors. We incorporate multiple biofuel pathways of interest, with those pathways that involve bioenergy crops analyzed in the integrated context of agriculture and land use. Finally, we assess the potential contribution of biofuels for helping to mitigate carbon dioxide emissions from air transportation in the context of the global energy system and discuss the importance of the use of carbon capture and storage (CCS) on total mitigation potential, something that we have not seen in the previous studies of biojet fuels.

\section{Methods}

For this analysis, we added a distinct jet fuel sector with biojet pathways to the standard release version 4 of the GCAM model (Kim et al. 2006, Clarke, et al. 2007, Edmonds and Reilly 1985), an integrated assessment model that links a global energy-economyagricultural-land-use model with a climate model. ${ }^{4}$ GCAM is a long-term model, typically operating in five-year time steps often through the year 2050 or 2100, depending on the time frame of focus. As part of GCAM's modeling of human activities and physical systems, GCAM tracks emissions and concentrations of the most relevant greenhouse gases and short-lived species (including $\mathrm{CO}_{2}, \mathrm{CH}_{4}, \mathrm{~N}_{2} \mathrm{O}, \mathrm{NO}_{\mathrm{x}}, \mathrm{VOCs}, \mathrm{CO}$, $\mathrm{SO}_{2}, \mathrm{BC}, \mathrm{OC}, \mathrm{HFCs}, \mathrm{PFCs}$, and $\mathrm{SF}_{6}$ ). GCAM 4 models the global energy system in 32 geo-political regions, with land use modeled in 283 sub-regions. Multiple resources of bioenergy are modeled in GCAM. Bioenergy can come from dedicated crops (e.g. energy grasses, woody biomass, corn, sugar, oil crops) that must compete economically for land for agriculture, forestry and other uses in each region, and bioenergy can also come from agriculture and forest residues and waste that scale with production of these commodities (Wise et al. 2014).

\subsection{Biojet Pathways: Technology Assumptions}

\footnotetext{
${ }^{3}$ While not addressed in this study, the aviation sector has higher environmental and climate change impact than is indicated by $\mathrm{CO}_{2}$ emission figures (Chapman, 2007, Krammer et al. 2013). This is due to other greenhouse gases $\left(e . g . \mathrm{NO}_{\mathrm{x}}\right)$ being released directly into the troposphere and lower stratosphere, where their effect is magnified and they may lead to localized effects that can be more damaging then the effects of $\mathrm{CO}_{2}$ alone (Cairns and Newson, 2006).

${ }^{4}$ Documentation for GCAM can be found at http://jgcri.github.io/gcam-doc/index.html. GCAM is a community model, available with its underlying data and source code at http:// www.globalchange.umd.edu/models/gcam/download/.
} 
The demand for jet fuel to meet domestic and international air transportation energy demands is modeled for each of the 32 socio-economic regions in GCAM. Demand for air travel is calibrated to historical demand in each region. Future growth in demand for air transport is determined in each model region by a combination of factors based on population, income, and fuel and other costs relative to other modes of transportation.

For this study, we have defined four specific but representative fuel technologies or pathways that compete in GCAM for the production of jet fuels. The competition is performed with a logit sharing mechanism based on energy sources and technology costs (Clarke and Edmonds 1993). These technologies include the conventional petroleumbased pathway as well as three biofuel pathways representative of major classes of technologies in terms of feedstocks and processing, as shown in Figure 1. These include a thermochemical (e.g., Fischer-Tropsch or FT) conversion of ligno-cellulosic biomass, Hydro-treated Esters and Fatty Acids (HEFA) from oil crops, and an ethanol to jet (ETJ) pathway, in which ethanol produced starting from corn is upgraded to meet the requirements of jet fuel. Ligno-cellulosic feedstock in GCAM can be supplied from residues in agriculture and forestry and from dedicated energy crops such as perennial grasses (e.g., switchgrass). We map the ETJ pathway to corn ethanol rather than cellulosic ethanol because corn ethanol is already produced at large scales and the FT option is available for cellulosic feedstock. As modeled here, the FT pathway has the additional option of employing CCS in the conversion of biomass feedstock to liquid fuel in response to a carbon price or emissions limit.

COMPETING TECHNOLOGIES

- Petroleum-based

- FT biofuels

- HEFA

- Ethanol-to-jet

\section{AIR TRANSPORT DEMANDS}

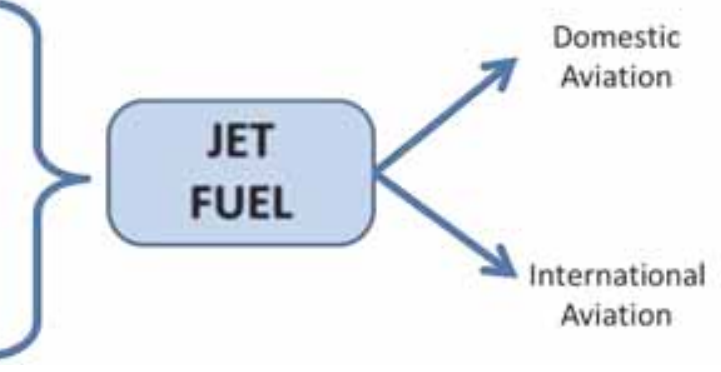

Figure 1. Jet fuel production pathways considered in this study.

We model these specific technologies to be more comprehensive and realistic, but the inclusion of technologies in this analysis should be considered a complement and not a 
substitute for more detailed chemical and techno-economic studies of these pathways. ${ }^{5}$ GCAM's role is not to analyze these technology systems in detail but instead to provide an integrated context considering the feedbacks and impacts among the inputs, outputs, and drivers of the competition between them. In that sense, this modeling study is more about the role of biojet fuels at large rather than a detailed comparative assessment of the potential of specific technologies.

Table 1 shows the jet fuel production assumptions for the four pathways considered. Feedstock input/output (I/O) assumptions and other energy input requirements for the four pathways are taken from the open literature: FT process from biomass and HEFA based on a camelina oil crop from Han et al. (2013); and Alcohol to Jet fuels via ethanol from Handler et al. (2013). Non-energy costs (i.e., levelized capital, materials, and operating and maintenance costs) are taken from Agustinata et al. (2011) and CCS coupled to FT cost adders are derived from Dooley and Dahowski (2009).

Table 1. Bio Jet Fuel Technologies: Fuel Production Assumptions.

\begin{tabular}{|l|c|c|c|c|}
\hline & Petroleum & FT & HEFA & ETJ Fuels \\
\hline Feedstock/Fuel [MJ/MJ] & 1.055 & $1.96-2.16$ & 1.3333 & 1.58 \\
\hline $\mathrm{H}_{2}$ use [MJ/MJ] & - & - & 0.1106 & - \\
\hline NG use [MJ/MJ] & 0.018 & - & 0.1827 & 0.318 \\
\hline Electricity use [MJ/MJ] & 0.005 & - & 0.0014 & 0.026 \\
\hline $\begin{array}{l}\text { Non-Energy Cost [2010 \$/ } \\
\text { GJ] }\end{array}$ & 2.9 & 7.4 & 6.7 & 8.2 \\
\hline $\begin{array}{l}\text { CCS Cost Adder [2010\$/ } \\
\text { GJ of jetfuel] }\end{array}$ & - & $0.7-1.17$ & - & - \\
\hline CCS Capture Efficiency & - & $80-95 \%$ & - & - \\
\hline
\end{tabular}

Each of the pathways in Table 1 will have some integration impacts to and from other parts of GCAM. All the biojet pathways will compete with other uses of bioenergy feedstocks in general. Many, except for the feedstocks from residues and wastes, will have an impact on the agriculture and land use, with consequent potential impact on food

${ }^{5}$ In choosing the number of pathways to model distinctly, we have to remain cognizant of GCAM's role as an integrating economic model rather than a techno-economic model. Technoeconomic models serve to illuminate and compare key engineering and system details and inform system optimization among alternate configurations. In contrast, GCAM's strength is in analyzing the competition between different classes of technologies and pathways. These classes have either different types of inputs, significantly different efficiencies, costs, or emissions or other characteristics that may be differentially affected by changing future economics or policies. 
and land use change emissions. All will require some process energy inputs from the energy sector, though some energy may be provided by biomass the feedstock itself.

\subsection{Scenarios}

We construct four scenarios of future global aviation fuel use and carbon emissions to 2050 by combining a pair of policy backgrounds with a pair of assumptions about the availability and viability of biojet fuel technologies. The first policy background is a reference case that assumes that there are no constraints on future carbon emissions from the energy system (no climate change mitigation). At the other bound is an illustrative carbon policy background that assumes there is a global limit on carbon emissions from fossil fuels and industrial processes. This carbon limit is implemented here as an idealized economically-efficient global cap with emissions trading among regions assumed. For the climate change mitigation policy modeled here, which is not reflective of any specific target being discussed in the policy world today, it is assumed that an emissions penalty, equal in all regions, is placed on all carbon emissions from the energy sector (including aviation) starting from 2020 in a manner that global fossil fuel and industrial emissions follow a smooth path of decline reaching a 50\% reduction relative to 2005 levels by 2050, as shown in Figure 2.

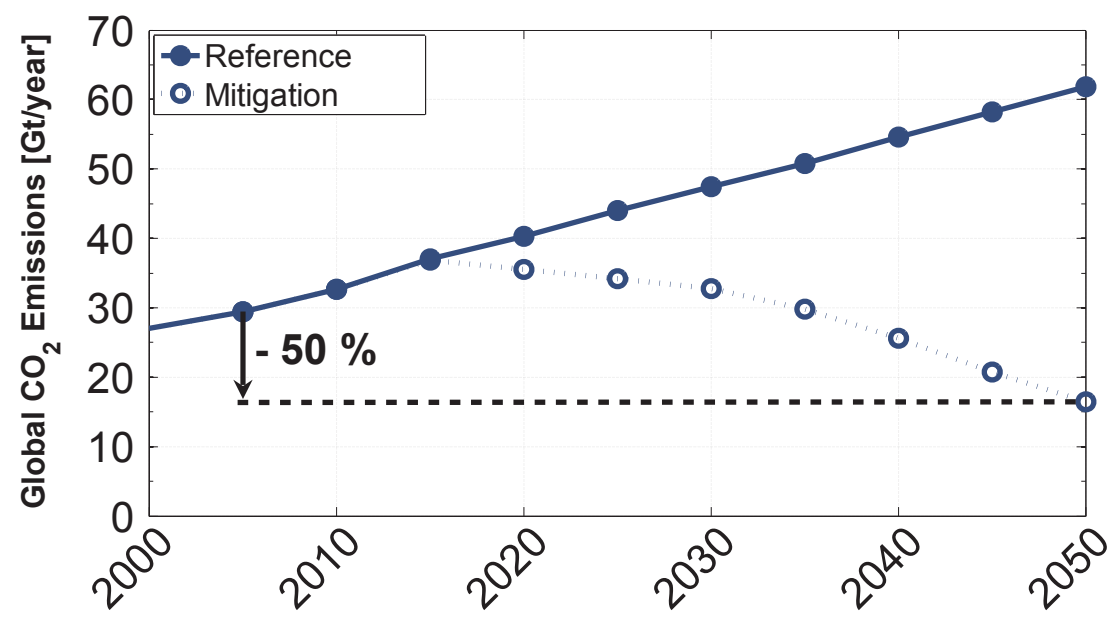

Figure 2. Global carbon dioxide emissions for the reference and climate change mitigation scenarios.

The two biojet cases are bounded quite simply by assuming in one case that biojet fuels are not viable and in the other case that biojet fuels are available at the technology assumptions and costs provided in Table 1. Table 2 reports the four scenarios created by combining the pairs of assumptions about climate change mitigation and biojet fuels availability. It is assumed through model calibration that current policies that incentivize bioenergy like the U.S. Renewable Fuels Standard are already met in the reference cases, and levels of biojet fuels in these scenarios are additional to those levels. 
Table 2. Scenario Definitions

\begin{tabular}{|l|l|l|}
\hline \multicolumn{1}{|c|}{ Scenario } & \multicolumn{1}{|c|}{ Climate Change Mitigation } & \multicolumn{1}{c|}{ Biojet Availability } \\
\hline “Reference, Fossil-jet” & Reference & None \\
\hline “Mitigation, Fossil-jet” & $50 \% \mathrm{CO}_{2}$ reduction by 2050 & None \\
\hline “Reference, Biojet” & Reference & Available \\
\hline “Mitigation, Biojet” & $50 \% \mathrm{CO}_{2}$ reduction by 2050 & Available \\
\hline
\end{tabular}

\section{Results}

GCAM estimates future regional demand for domestic and international aviation based on modeled representations of population growth, economic growth, and the future costs of air travel relative to other transportation modes based on technology assumptions, and fuel costs, including policies that may affect fuel costs (e.g. carbon price). Model results for 2010 are calibrated to match historical data. Aviation demand (total demand indexed to 2010 levels) for the "Reference, Fossil-jet" scenario is shown in Figure 3, aggregated from GCAM's 32 regions to larger regional groupings. In this scenario, global demand for aviation services grows by a factor of 4 from 2010 to 2050. Currently, Europe and the U.S. account for much of the global demand for aviation. However, the majority of the projected growth is in the currently developing economies.

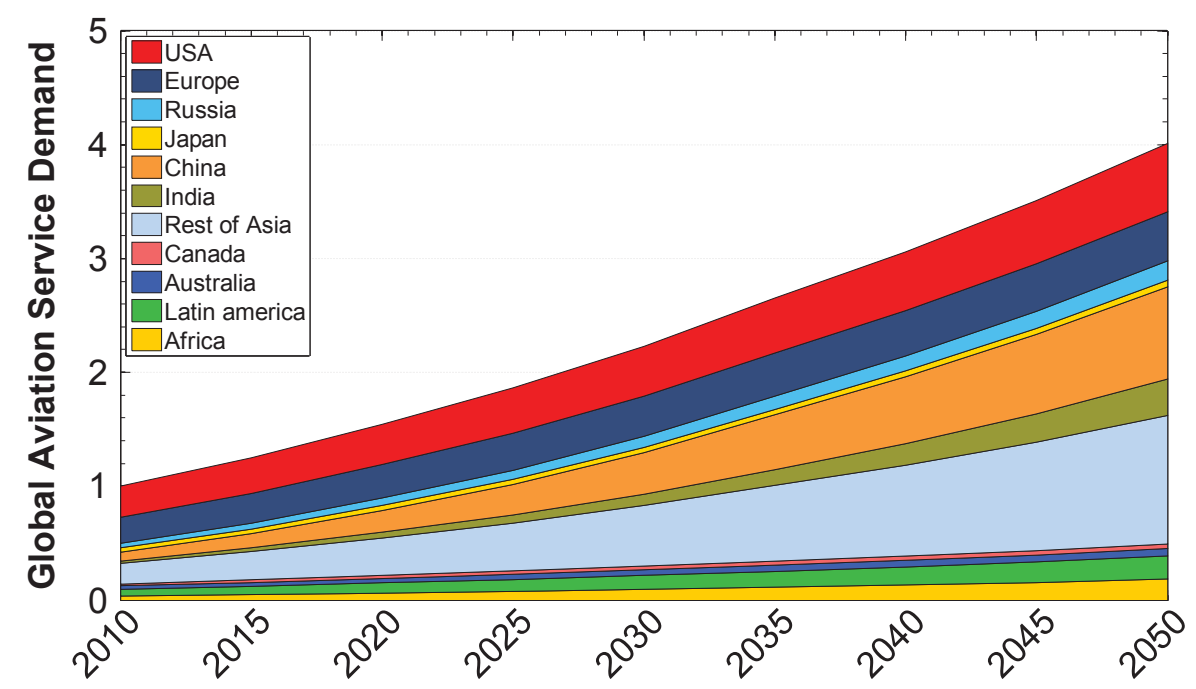

Figure 3. Global aviation service demand growth, including both domestic and international travel. "Reference, Fossil-jet" scenario (Index with $2010=1$ ). 
Global fossil fuels and industrial carbon dioxide emissions for the different scenarios are reported in Figure 4, with the total energy system emissions on the left panel and global transportation sector emissions on the right panel. The carbon emissions paths in the "Reference, Fossil-jet" and "Reference, Biojet" scenarios are projected in the absence of any carbon price, and can be considered as reference cases in the absence of a policy that mitigates carbon emissions. In these scenarios, global total emissions in the left panel grow steadily reaching a level by 2050 nearly double the level in 2005. Although difficult to discern from the figure, the "Reference, Biojet" scenario has emissions just slightly lower than the "Reference, Fossil-jet" scenario. The difference in these scenarios is the availability of biojet fuels in the "Reference, Biojet" scenario. The small size of the difference is partly an indication of the relative size of the aviation emissions relative to the global energy system, and partly a signal about the limited penetration of biojet fuels in the absence of a carbon price. Also in the left panel, the emissions paths for the climate change mitigation scenarios ("Mitigation, Fossil-jet" and "Mitigation, Biojet") are identical, as they are prescribed in the scenario definitions for this study. These paths peak in 2015 and steadily decline to reach a level approximately 50\% below 2005 levels by 2050 .

On the right panel of Figure 4, the transportation sector (comprising all passenger and freight road, rail, aviation, ship, and anything else in the transportation sector) shows more difference between scenarios. The two reference cases again show similar results, though the relative impact of the biojet in aviation appears larger when measure against just the transportation sector total. In stark contrast to the aviation sector emissions shown later, the transportation sector emissions drop substantially in in both mitigation scenarios, with and without biojet.
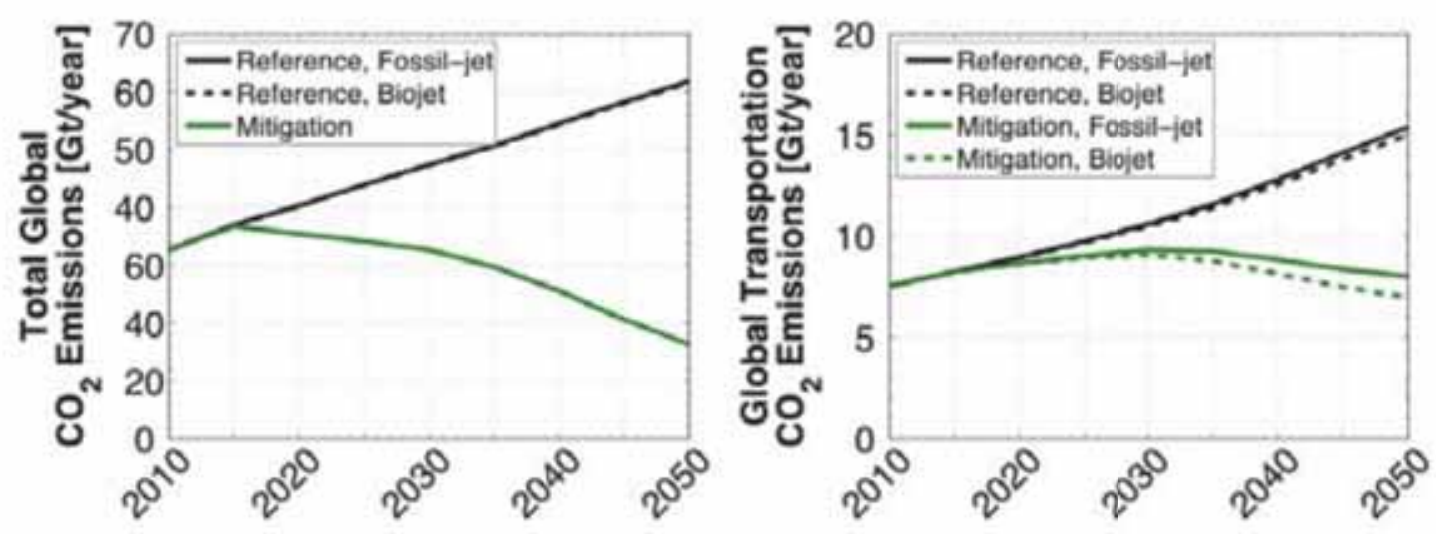

Figure 4.Global fossil fuel and industrial $\mathrm{CO}_{2}$ emissions for the two reference scenarios and for the mitigation scenarios. Total all energy sectors (Left Panel), Transportation sector (Right Panel)

The $\mathrm{CO}_{2}$ emissions paths in the mitigation scenarios are implemented in the model as idealized, generic constraints that GCAM meets by solving for the economically efficient set of actions among all sectors and regions considering demand growth and the cost of 
alternative technologies. In the real world, this approach is equivalent to a global agreement in which all regions face a common carbon price path and make demand and technology choices accordingly. In modeling terminology, this carbon price path is equivalent to the shadow price of the global carbon constraint, and it can be interpreted generally as an indication of the cost of reducing emissions rather than as a literal implementation of a specific policy. Figure 5 shows the carbon price paths solved for by GCAM in the climate change mitigation scenarios. First note that these carbon prices grow to nearly $\$ 125 /$ tonne of $\mathrm{CO}_{2}$ in 2050, indicative of the stringency of such an emissions reduction target. But also note that the carbon prices for the "Mitigation, Biojet" scenario are only slightly below those of the "Mitigation, Fossil-jet" scenario. Again this slight difference is due to the availability of the biojet fuels. The presence of the biojet options, all else equal, will lower the price to meet the same carbon emissions target. However, the very slight difference in carbon price is also reflective of the small relative size of aviation emissions relative to the global energy system.

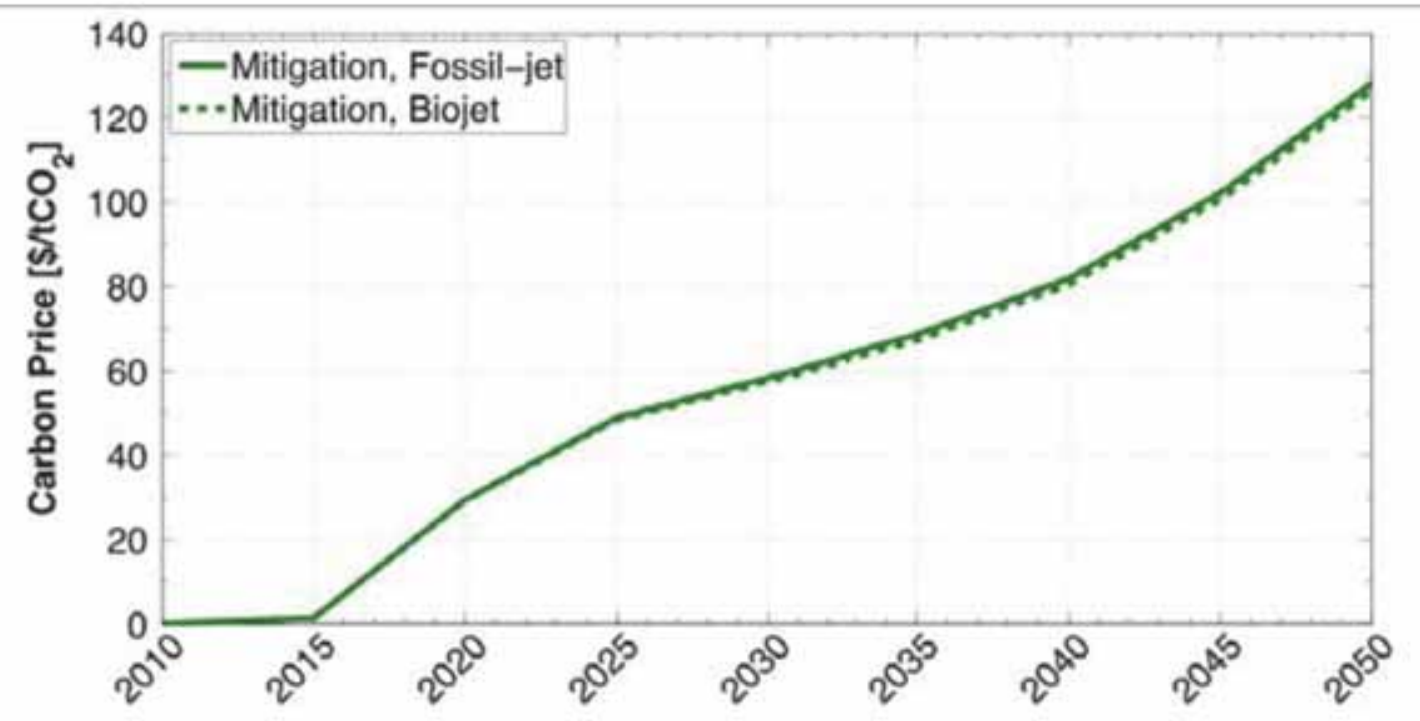

Figure 5. Global carbon price (2010 US\$/tonne $\mathrm{CO}_{2}$ ) pathways in the two climate change mitigation scenarios 
Focusing on the aviation sector, Figure 6 shows the global aviation fuel consumption by type for each of the four scenarios. In the "Reference, Fossil-jet" scenario, in the absence of a carbon price or any biojet options, fossil jet fuel grows by about a factor of three over the time period of 2010 to 2050 . Note that, although this growth is substantial, it is less that the four-fold growth in aviation service demands (see Figure 3). This reflects increasing efficiency and utilization rates assumed for future air travel in GCAM. The introduction of a carbon price increases aviation service costs, which depresses its growth and the global jet fuel use, as illustrated in the "Mitigation, Fossil-jet" scenario. In this study, advanced plane technologies or aviation system designs for meeting aviation service demand with less fuel are not modeled explicitly (see Sims et al. (2014) for a comprehensive set of options). Instead, the reduction in fuel use is primarily a result of decreased demand for air travel as it becomes more costly. This lack of aircraft detail is a slight shortcoming as Dray (2014) concludes that aviation emissions could be reduced by $9 \%$ by replacing current aircraft with newer technology. However, with the long lead times for planning, development, and capital stock turnover this replacement would be limited in practice.

Turning to the scenarios in which biojet fuels are available (bottom panels in Figure 6), in the "Reference, Biojet" scenario biojet becomes sufficiently competitive with fossilbased jet fuels that it gains a growing share of the market for aviation fuels. By 2050, the share of biojet reaches about $15 \%$ of the global total, reflecting improving technology for biojet production and increasing oil prices. Based on the economics resulting from the technology assumptions in Table 1, about 95\% of this biojet comes from FT of lingocellulosic biomass, with a small amount from ETJ and HEFA. Under a carbon target, biojet gains about $40 \%$ of the market for aviation fuels by 2050 in the "Mitigation, Biojet" scenario, and due its favorable economics and especially to its CCS option, almost all of the biojet fuel comes from FT. 

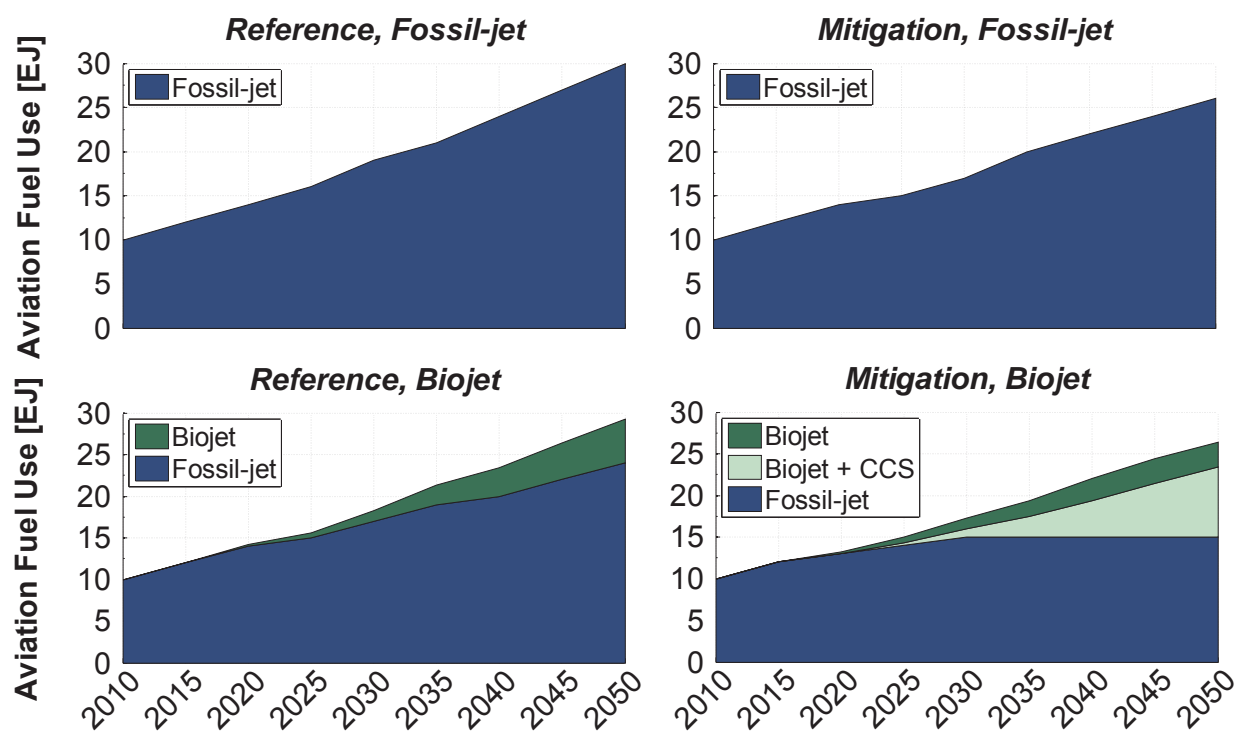

Figure 6. Global jet fuel use by fuel in the four scenarios.

Two results in the "Mitigation, Biojet" scenario deserve special mention. One is that the total demand for jet fuel is still depressed by the carbon price, even if biojet fuels are available. Biojet fuels have higher costs than conventional fossil-based jet fuels in these scenarios, mainly due to higher conversion costs and lower efficiency assumptions. Improving these technologies would serve to mitigate this demand reduction for aviation, to some extent. The second result is the large share of biojet with CCS that becomes economically viable under high carbon prices. As will be seen next, this has a large impact on the aviation sector net carbon emissions.

Figure 7 shows the impact of climate change mitigation and of the fuel mix in the aviation sector on global aviation carbon emissions. In scenarios in which jet fuel is only supplied by fossil fuels, the carbon emissions path mirrors the fossil fuel use path. Carbon emissions grow by a factor of three in the "Reference, Fossil-jet" scenario, matching the fuel growth. Carbon emissions are nearly 20\% lower by 2050 in the "Mitigation, Fossiljet" scenario, due mainly to demand reductions. Also noted comparing Figure 7 to Figure 4 is that global aviation sector carbon emissions remain less than $5 \%$ of total energy sector emissions. Finally, in comparing the aviation sector emissions to the total transportation sector emissions in the right panel of Figure 4, it can be inferred from the total emissions reductions in the "Mitigation, Fossil-jet" scenario that the rest of the transportation sector has more cost effective options for mitigating such as electrification in addition to biofuels. These results are quite similar to those in Winchester et al. (2011) who found in their modeling study that U.S. aviation sector emissions under a carbon price of about $\$ 90 /$ tonne of $\mathrm{CO}_{2}$ grow to approximately double 2010 levels by 2050: a reduction of $18 \%$ below their reference case aviation sector emissions in 2050 . 


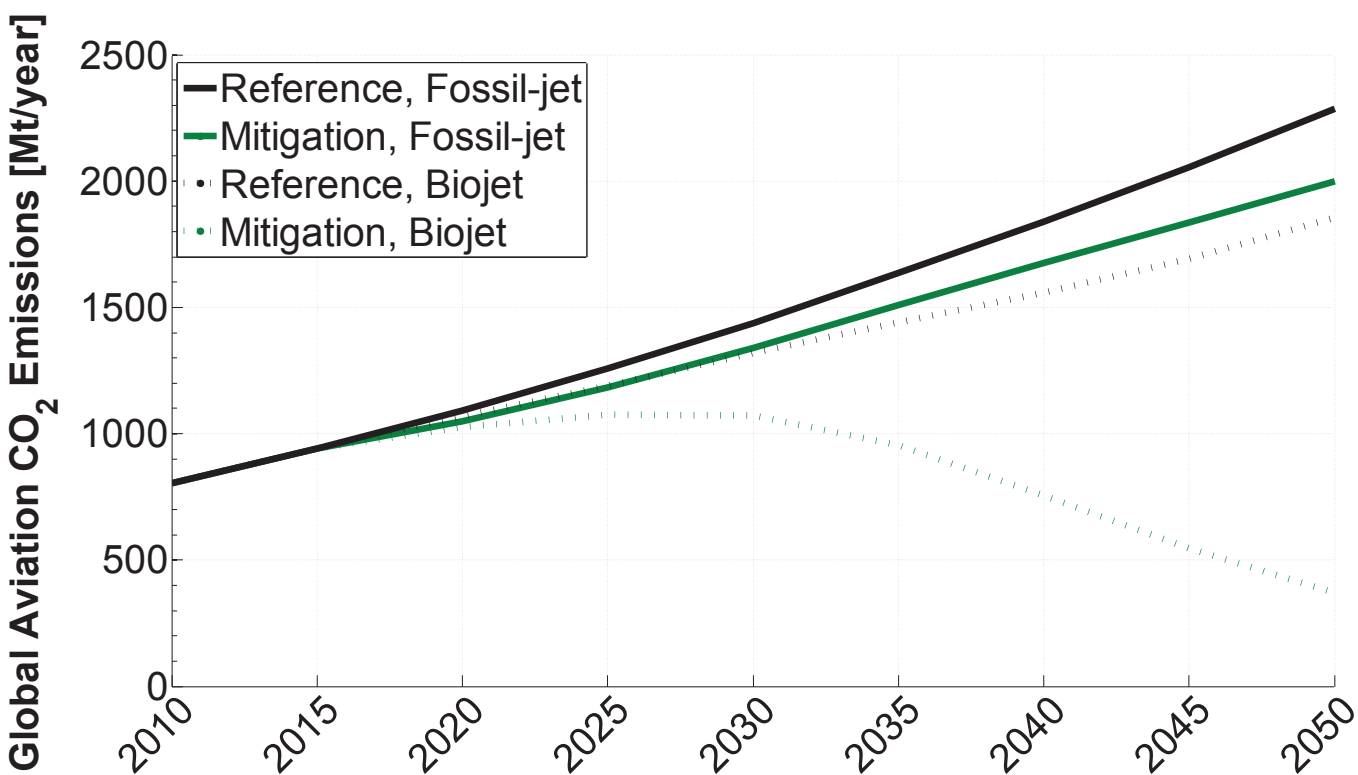

Figure 7. Global aviation carbon dioxide emissions for the four scenarios considered.

In analyzing the carbon emissions from scenarios where biojet fuels are available ("Reference, Biojet" and "Mitigation, Biojet"), some explanation and assumptions about GCAM's treatment of carbon emissions from fossil jet fuel and bioenergy is helpful. For fossil jet fuel, the emissions shown in Figure 7 are the sum of "direct" emissions generated in the aviation sector as well as emissions from energy inputs to refining. As for bioenergy in GCAM, the net carbon emissions from combusting bioenergy are typically assumed to be net zero, as the carbon that is vented during the combustion is offset by the biomass intake from the atmosphere when the biomass was grown. In a steady state of growing, harvesting, and using bioenergy in the energy system, the net carbon from the bioenergy itself is zero. This is distinct from terrestrial carbon emissions that can result from direct and indirect land use change as land devoted to bioenergy is expanded, which are also accounted for in GCAM. Also, emissions from any fossil fuel input requirements to bioenergy refining are also accounted for here.

In the "Reference, Biojet" scenario, the penetration of biojet fuels reduces emissions by about 100 million metric tonnes in 2050. Interestingly, this reduction is higher than that achieved by the carbon price in the "Mitigation, Fossil-jet" scenario, considering aviation emissions only. In the "Mitigation, Biojet" scenario, however, the aviation carbon emissions reduction are quite substantial, close to the $50 \%$ reduction target for the overall energy system. Much of this large reduction is due to the production of biojet fuels with CCS and crediting the carbon sequestered in that process to the aviation sector. Based on the conversion efficiency assumed here for FT production of jet fuel, it takes roughly two GJ of biomass feedstock to produce one GJ of biojet fuel. Although the carbon contained in the biojet fuel is vented at the "tailpipe" when the fuel is combusted, 
the carbon dioxide that is released in the conversion process is captured and sequestered in underground formations.

With the assumption that bioenergy has a net zero carbon emissions impact, bioenergy with CCS a net carbon sink as carbon that is taken from the atmosphere to grow the biomass feedstock is permanently sequestered underground during the bioenergy conversion process (when liquid fuels are produced). In very round numbers, a unit of biojet with CCS roughly offsets the carbon emissions from a unit of fossil jet fuel. Looking at the jet fuel mix results for the "Mitigation, Biojet" scenario in Figure 6, by 2050 there is nearly half as much biojet with CCS as there is fossil jet fuel. With the biojet with CCS offsetting the emissions from half of the fossil jet fuel, the net carbon emissions from aviation reach a level about 50\% below current levels. However, it must be stated that the both the viability and the economic impact of large-scale deployment of CCS is uncertain (see for example Muratori et al. 2016, Klein et al. 2014, and Koelbl et al. 2014). If the biojet fuels used in this scenario were not produced using CCS, the aviation sector carbon emissions would simply follow the pattern of the fossil jet fuel path in Figure 6 and be more than double the level shown by $2050^{6}$.

Although the scenarios here are not designed as controlled model experiments to isolate the marginal impact on emissions of a specific increase in bioenergy (see Wise et al. 2015), it is still useful compare land use change carbon emissions between the scenarios to assess their general magnitude relative to energy system emissions reductions. Figure 8 shows the annual difference in global land use change carbon emissions between the "Mitigation, Biojet" and the "Mitigation, Fossil-jet" scenarios. Although land use change has complex dynamic implications across multiple time periods, it is clear from Figure 8 that the magnitude of the increased land use change emissions is small relative to the reductions achieved in the aviation sector in Figure 7, on the order of 10 to $20 \%$.

However, it should be noted that for this study we assumed for conservative sustainability purposes that $90 \%$ of all unmanaged or non-commercial lands such as forest and grasslands would be excluded from commercial agricultural expansion. The background land use policy is critical to the assessment of land use change emissions from bioenergy (Wise et al. 2015), and without this assumption, land use change emissions would be clearly higher.

${ }^{6}$ A full scenario without CCS available to the energy system was also constructed. However, it was such a drastically different scenario with much higher carbon prices and impacts on the entire energy system that it was not a useful comparison in focusing on biojet fuels. 


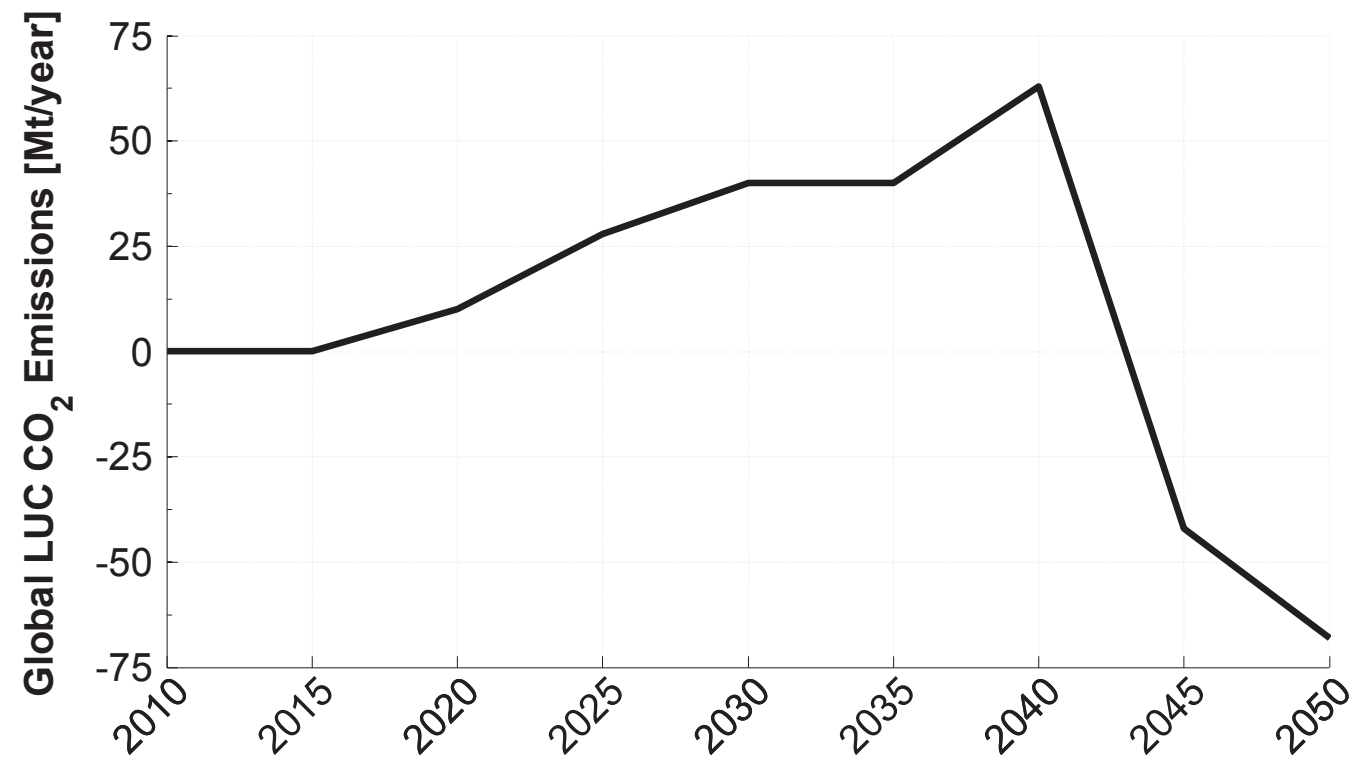

Figure 8. Net increase in land use change emissions in the carbon policy scenarios with and without biojet fuels: "Mitigation Biojet" Vs. "Mitigation Fossil-jet” scenarios.

Finally, we compare the amount of bioenergy used for biojet fuels to the amount of bioenergy used in all energy sectors under the climate change mitigation scenario ("Mitigation, Biojet" scenario). This comparison provides additional context on the potential impact and interactions between aviation's use of bioenergy in competition with other sectors of the economy. Global consumption of bioenergy by sector for the "Mitigation, Biojet" scenario is reported in Figure 9. In the 2010 base year, most bioenergy is consumed in the industrial sector. As technology changes, and especially as the costs of using fossil fuels increases due to the carbon price increases, the use of bioenergy expands to other sectors. Bioenergy use remains relatively low and constant for direct use in buildings. Industrial use of bioenergy remains relatively constant for a couple of decades, but it starts to decline by 2035 as the increasing carbon prices give bioenergy higher value for use in fuels for transportation and for use in generating electricity. Some of this increase is due to the availability of CCS technologies coupled to power plants and liquid fuel production plants, which make bioenergy more economically attractive due to the credit deriving from net negative emissions. Even without CCS, the lack of economic alternatives to decarbonize the transportation sector put upward pressure on the demand for biofuels, leading to a shift from use of biomass in industry to the production of low-carbon liquid fuels for use primarily in transport. 
Draft February 26, 2017 Revised Submission to Transportation Research Part D

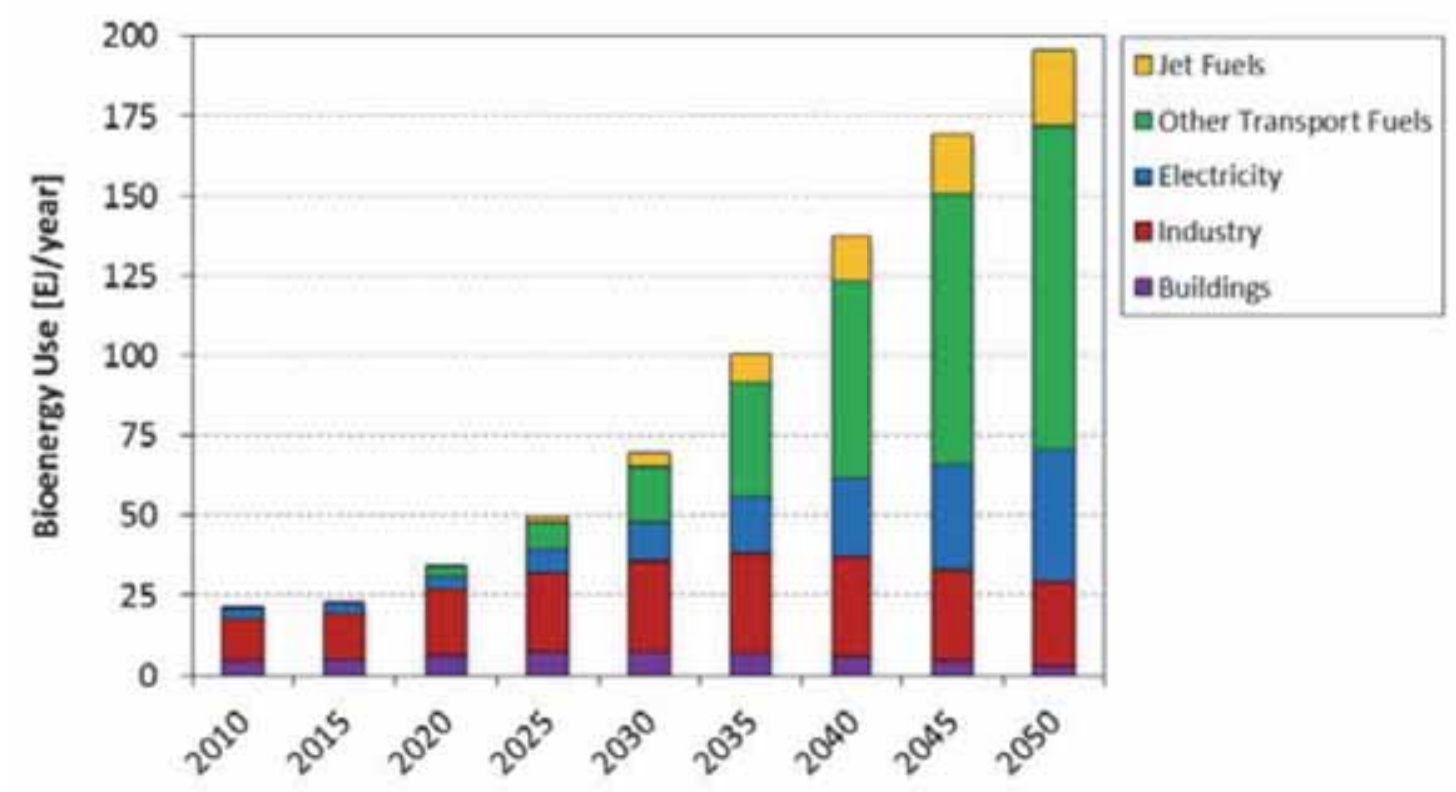

Figure 9. Global use of bioenergy by sector in the "Mitigation, Biojet” scenario.

As to the impact of the aviation sector's use of bioenergy, the amount of bioenergy used is significant within that sector in terms of reducing fossil energy use and carbon emissions. However, the amount of bioenergy used for jet fuel comprises only about $10 \%$ of the global total bioenergy consumed. This suggests that, at least on the large global context, biojet fuel use would not have a major impact on the demand and cost of biomass in other parts of the energy system under a climate change mitigation policy implemented via a uniform carbon price on fossil fuel and industrial emissions. ${ }^{7}$

\section{Conclusion}

We have used the GCAM integrated assessment model to develop scenarios that explore the potential impact of biojet fuels in a growing global demand for aviation fuels and in the context of climate change mitigation. We have shown that, although demand is growing, carbon emissions from aviation will continue to be a small percentage of total global emissions from the energy system. Because of its relatively small contribution to the total, mitigation efforts within the aviation sector through the increased use of biojet fuels would not have a significant crowding out effect on bioenergy use and other mitigation efforts in the rest of the energy system. In our results, carbon prices were only marginally reduced by the availability of biojet fuels, and bioenergy consumption for aviation was only about $10 \%$ of the total bioenergy demand under a climate change mitigation scenario reducing $\mathrm{CO}_{2}$ emissions in 2050 to half of the emissions in 2005.

${ }^{7}$ Pricing of terrestrial carbon emissions would significantly change the role of bioenergy in general (Wise et al. 2009). 
We also showed, however, that even though its emissions are small, a global carbon price would have a significant impact on the aviation sector. In the absence of alternatives to jet fuel from fossil sources, in a climate change mitigation scenario that limits $\mathrm{CO}_{2}$ emissions in 2050 to half of the emissions in 2005, the aviation sector emissions are reduced by only about $10 \%$ relative to the unconstrained case (i.e. without carbon price) while the rest of the energy system achieves much deeper reductions. In this scenario, the decrease in emissions in the aviation sector comes from a decrease in the rate of growth of aviation service demand, while still maintaining a high carbon intensity based on fossil fuel use. This result is also an indication that the aviation system is more costly to decarbonize in the absence of economical alternatives to liquid fossil fuels.

Finally, we showed the potential of biojet fuels to greatly reduce the carbon intensity of aviation. This potential is especially true when CCS is used in the conversion process from biomass feedstock to liquid jet fuels. In our analysis, the production of biojet fuels with CCS leads to net negative carbon emissions for each unit of fuel produced. The net negative emissions partially offset the carbon emissions from fossil fuel use, and the viability of CCS greatly enhances the mitigation potential of biojet fuels. However, largescale deployment of CCS remains questionable. Achieving the same emissions reduction objective without CCS implies significantly higher carbon price, which leads to demand suppression for aviation services and increased use of biojet fuels, if available, since the lack of net negative emissions reduces the emissions mitigation potential of bioenergy.

\section{Acknowledgements}

This research is based on work supported the Bioenergy Technologies Office (BETO) of the United States Department of Energy (DOE). The Pacific Northwest National Laboratory is operated for DOE by Battelle Memorial Institute under contract DEAC05-76RL01830. The views and opinions expressed in this paper are those of the authors alone. 


\section{References}

Agusdinata et al. (2011). Agusdinata, Datu B., Fu Zhao, Klein Ileleji, and Dan DeLaurentis. "Life cycle assessment of potential biojet fuel production in the United States." Environmental science \& technology 45, no. 21 (2011): 9133-9143.

Boeing (2015). Current Market Outlook, 2015 - 2034 (online, available: http:// www.boeing.com/resources/boeingdotcom/commercial/about-our-market/assets/ downloads/Boeing_Current Market Outlook 2015.pdf)

Cairns and Newson, (2006). Cairns, S., Newson, C. "Predict and decide". Aviation, Climate Change and UK Policy, Environmental Change Institute, 122pp. 2006.

Chapman, Lee (2007). "Transport and climate change: a review". Journal of transport geography 15.5 (2007): 354-367.

Civil Aviation Organization (2012). U.S. Aviation Greenhouse Gas Emissions Reduction Plan. https://www.faa.gov/about/office_org/headquarters_offices/apl/ environ_policy_guidance/policy/media/ Aviation_Greenhouse_Gas_Emissions_Reduction_Plan.pdf. Retrieved September 23, 2015.

Clarke and Edmonds (1993). Clarke, J. F., Edmonds, J. A., 1993. Modeling energy technologies in a competitive market. Energy Economics 15, pp. 123-129.

Clarke et al. (2007). Clarke, L., J. Lurz, MA Wise, JA Edmonds, SH Kim, SS Smith, HM Pitcher. Model Documentation for the MiniCAM Climate Change Science Program Stabilization Scenarios: CCSP Product 2.1a. PNNL Technical Report. PNNL-16735, 2007.

Clarke et al. (2014). Clarke L., K. Jiang, K. Akimoto, M. Babiker, G. Blanford, K. FisherVanden, J.-C. Hourcade, V. Krey, E. Kriegler, A. Löschel, D. McCollum, S. Paltsev, S. Rose, P. R. Shukla, M. Tavoni, B. C. C. van der Zwaan, and D.P. van Vuuren, 2014: Assessing Transformation Pathways. In: Climate Change 2014: Mitigation of Climate Change. Contribution of Working Group III to the Fifth Assessment Report of the Intergovernmental Panel on Climate Change [Edenhofer, O., R. Pichs-Madruga, Y. Sokona, E. Farahani, S. Kadner, K. Seyboth, A. Adler, I. Baum, S. Brunner, P. Eickemeier, B. Kriemann, J. Savolainen, S. Schlömer, C. von Stechow, T. Zwickel and J.C. Minx (eds.)]. Cambridge University Press, Cambridge, United Kingdom and New York, NY, USA.

Dooley and Dahowski (2009). Dooley, James J., and Robert T. Dahowski. "Large-scale US unconventional fuels production and the role of carbon dioxide capture and storage 
technologies in reducing their greenhouse gas emissions." Energy Procedia 1.1, 2009, 4225-4232. (http://www.sciencedirect.com/science/article/pii/S1876610209008765)

DOT (2012). “Alternative Jet Fuel Scenario Analysis Report.” http://ntl.bts.gov/lib/ 46000/46500/46597/DOT-VNTSC-FAA-12-01.pdf.

Dray, L.M. (2014). “Time constants in aviation infrastructure.” Transport Policy 34 (2014) pp. 29-35.

Dray, L.M., Evans, A., Reynolds, T.G., Schäfer, A., Vera-Morales, M. (2014). “Airline fleet replacement funded by a carbon tax: An integrated assessment." Transport Policy 34 (2014) pp. 75-84.

Edmonds and Reilly (1985). Edmonds, J., Reilly, J. Global Energy - Assessing the Future, Oxford University Press, Oxford, 1985.

EU (2013). DECISION No 377/2013/EU OF THE EUROPEAN PARLIAMENT AND OF THE COUNCIL. 24 April 2013 http://eur-lex.europa.eu/legal-content/EN/TXT/PDF/? uri=CELEX:32013D0377\&from=EN. Retrieved September 23, 2015.

Han et al. (2013). Han, J., A. Elgowainy, H. Cai, M Wang. "Life-cycle analysis of biobased aviation fuels.” Bioresource Technology, 150, 2013, pp. 447-456.

Handler, R. et al.(2014). "Life Cycle Assessments of Jet Fuel and Co-Products Made from Lanzatech Biomass-Based Ethanol”, AIChe Annual Conference.

Hofer et al. (2010). Hofer, C., M. Dresner, and R. Windle. "The environmental effects of airline carbon emissions taxation in the U.S." Transportation Research Part D (Transport and Environment), 15, 2010, pp. 37-45.

IATA (2015). IATA Annual Review 2015. (online, available: http://www.iata.org/about/ Documents/iata-annual-review-2015.pdf)

IATA (2015b). IATA Sustainable Aviation Fuel Roadmap. International Air Transport Association, Geneva. (Online, available: http://www.iata.org/whatwedo/environment/ Documents/safr-1-2015.pdf).

Kim et al. (2006). Kim, SH, JA Edmonds, J Lurz, SJ Smith, and MA Wise. "The Objectoriented Energy Climate Technology Systems (ObjECTS) Framework and Hybrid Modeling of Transportation in the MiniCAM Long-Term, Global Integrated Assessment Model," The Energy Journal, Special Issue: Hybrid Modeling of Energy-Environment Policies: Reconciling Bottom-up and Top-down, 2006, pp.63-91. 
Klein, D., Luderer, G., Kriegler, E., Strefler, J., Bauer, N., Leimbach, M., Popp, A., Dietrich, J.P., Humpenöder, F., Lotze-Campen, H. and Edenhofer, O. (2014). The value of bioenergy in low stabilization scenarios: an assessment using REMIND-MAgPIE. Climatic Change, 123(3-4), pp.705-718.

Koelbl B S, van den Broek M A, Faaij A P and van Vuren D P (2014). "Uncertainty in carbon capture and storage (CCS) deployment projections: a cross-model comparison exercise." Climatic Change 123 461-76.

Krammer, Philip, Lynnette Dray, Marcus O. Köhler (2013). “Climate-neutrality versus carbon-neutrality for aviation biofuel policy." Transportation Research Part D, 23 (2013) pp. 64-72.

Mayor K, and RSJ Tol (2010). "The impact of European climate change regulations on international tourist markets." Transportation Research Part D: Transport and Environment 15, 26-36. doi: 10.1016/j.trd.2009.07.002, ISSN: 1361-9209.

McCollum et al. (2010). McCollum, David L., Gregory Gould, and David L. Greene. "Greenhouse gas emissions from aviation and marine transportation: Mitigation potential and policies." Institute of Transportation Studies (2010).

Milbrandt et al. (2013). Milbrandt, A., C. Kinchin, and R. McCormick. The Feasibility of Producing and Using Biomass-Based Diesel and Jet Fuel in the United States. National Renewable Energy Laboratory. NREL/TP-6A20-58015, 2013.

MIT (2014). MIT Laboratory for Aviation and the Environments, 2014. http://lae.mit.edu/ alternative-fuels/.

Muratori, Matteo, Katherine Calvin, Marshall Wise, Page Kyle, and Jae Edmonds (2016). "Global economic consequences of deploying bioenergy with carbon capture and storage (BECCS)," Environmental Research Letters, Volume 11, Number 9, Page 095004, 2016.

Schäfer, Andreas W. and Ian A. Waitz (2014). "Air transportation and the environment." Transport Policy 34 (2014), pp. 1-4.

Sims et al. (2014). Sims R., R. Schaeffer, F. Creutzig, X. Cruz-Núñez, M. D’Agosto, D. Dimitriu, M.J. Figueroa Meza, L. Fulton, S. Kobayashi, O. Lah, A. McKinnon, P. Newman, M. Ouyang, J.J. Schauer, D. Sperling, and G. Tiwari (2014). Transport. In: Climate Change 2014: Mitigation of Climate Change. Contribution of Working Group III to the Fifth Assessment Report of the Intergovernmental Panel on Climate Change [Edenhofer, O., R. Pichs-Madruga, Y. Sokona, E. Farahani, S. Kadner, K. Seyboth, A. Adler, I. Baum, S. Brunner, P. Eickemeier, B. Kriemann, J. Savolainen, S. Schlömer, C. von Stechow, T. Zwickel and J.C. Minx (eds.)]. Cambridge University Press, Cambridge, United Kingdom and New York, NY, USA. 
Winchester et al. (2011). Winchester, Niven, Christoph Wollersheim, Regina Clewlow, Nicolas C. Jost, Sergey Paltsev, John M. Reilly, Ian A. Waitz (2011). The Impact of Climate Policy on US Aviation. http://web.mit.edu/aeroastro/partner/reports/proj31/ proj31-captraderpt.pdf. Retrieved September 24, 2015.

Wise et al. (2009). Wise, M., Calvin, K., Thomson, A., Clarke, L., Bond-Lamberty, B., Sands, R., Smith, S.J., Janetos, A. and Edmonds, J. "Implications of limiting $\mathrm{CO}_{2}$ concentrations for land use and energy". Science 324(5931):1183-1186.

Wise, M.A., J.J. Dooley, P. Luckow, K. Calvin, and P. Kyle. (2014). Agriculture, land use, energy and carbon emission impacts of global biofuel mandates to mid-century. Applied Energy. Volume 114, February 2014. pp. 763-773. doi: 10.1016/j.apenergy.2013.08.042.

Wise et al. (2015). Wise, M., Hodson, E., Mignone, B., Clarke, L., Waldhoff, S., Luckow, P. "An approach to computing marginal land use change carbon intensities for bioenergy in policy applications." Energy Economics, Volume 5, 2015. Pp 337-347. 